\title{
Cerclage technique for dynamic eyelid closure in facial paralysis
}

\author{
F. P. ENGLISH AND J. V. T. APEL
}

Department of Ophthalmology, Repatriation Hospital, University of Queensland, Australia

The ophthalmic surgeon's approach to the eyelid problem associated with facial nerve paralysis is by tradition a conservatively static one. A number of procedures have been devised, a standard example of which is the tarsorrhaphy.

More recently a refreshing new dynamic approach to this disabling condition has arisency in the continent of Europe. These techniques derived from France attempt to restore $-\overrightarrow{0}$ the proper synergism of eyelid movement, and to improve cosmesis, while respecting the importance of the tear-film.

The palpebral spring invented by Morel-Fatio is a satisfactory device for restoring lid옥 movement, and has enjoyed considerable success in Europe, North America, and Australia $\vec{\circ}$ (Morel-Fatio and Lalardrie, I967; Guy and Ransohoff, I968; Smith and Cherubini, I970;용 English and English, I972; Levine, House, and Hitselberger, 1972). However, where there is marked involvement of the lower eyelid, the cerclage technique (Arion, 1972) dis $\vec{\oplus}$ to be preferred. This applies also when a palpebral spring has to be removed in the eve of erosion or rejection.

\section{Procedure}

The cerclage procedure is a simple one, which like the eyelid spring requires the cooperation of the patient, and is consequently performed under local anaesthesia. Excessive infiltration of the $\mathcal{D}$ anaesthetic agent is to be avoided as this may hamper eyelid movement.

Basically two incisions are made (Fig. I), the first in the medial canthus area to display the medial canthal ligament, and the second over the lateral border of the orbit, extended deeply to demonstrate the orbital rim.

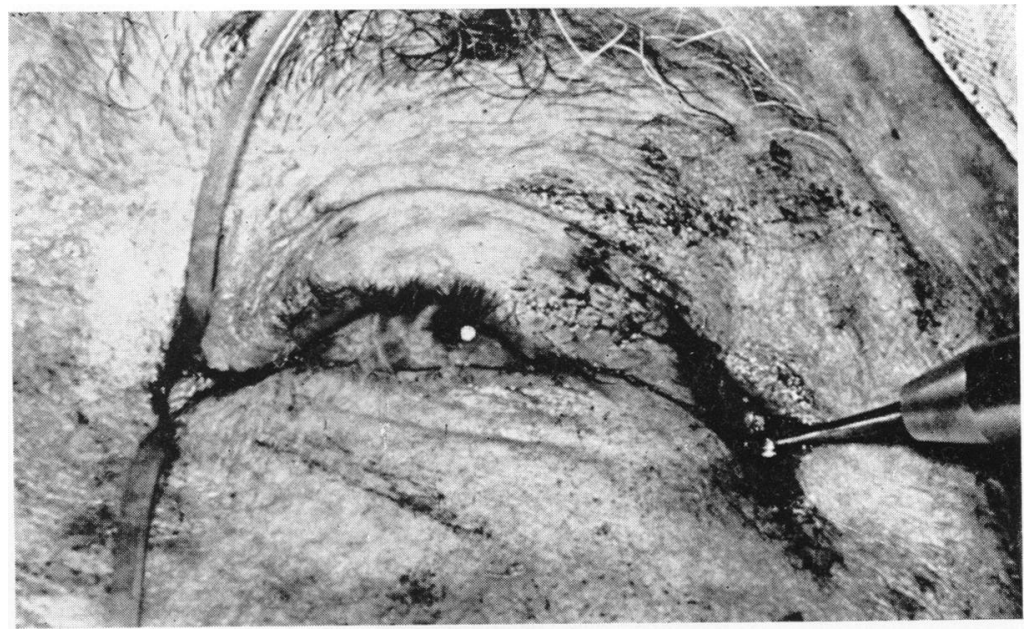

FIG. I Silicone band anchored in medial canthal ligament while drill $\mathrm{N}$ site is being prepared 
A useful cerclage element possessing the necessary physical requirements is the silicone strap as utilized in retinal surgery. This is threaded on to a needle and a firm bite of the exposed medial canthal tendon is taken. The silicone strap is then pulled through, this producing firm anchorage in the nasal region.

With a dental drill, a hole is prepared in the lateral orbital wall in the vicinity of Whitnall's tubercle. The surgeon estimates this site at a level corresponding with the medial attachment of the cerclage.

Fine stainless steel wire is introduced into the bony opening, and its medial end is attached to a large needle contoured to the curve of the eyelid. The needle is then passed in a nasal direction between the skin and tarsus, aiming to create a tract at the mid level of the upper tarsal plate. The point of exit is at the internal angle of the eyelid and the wire is attached to the silicone band. This latter manoeuvre is facilitated by making an opening in the cerclage and threading the wire through, thus ensuring firmer purchase.

The wire is then pulled back along the pre-existing track (Fig. 2) and taken through the bony canal to externalize the silicone thread. A similar procedure is repeated for the lower eyelid.

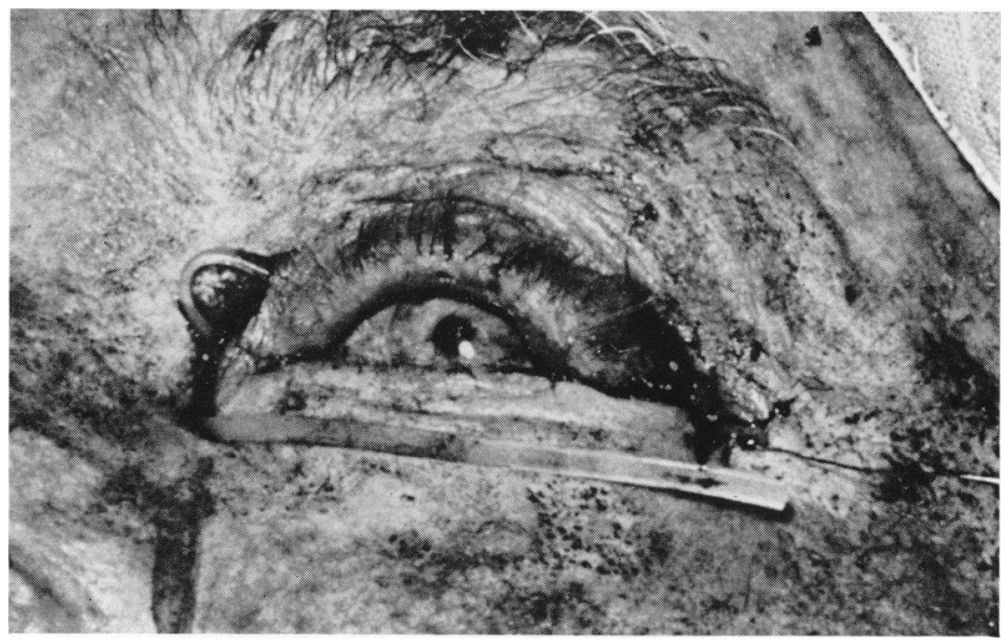

FIG. 2 Pulling the silicone element with fine wire along the prepared tract

It is at this stage that the cooperation of the patient is elicited, and he is requested to perform successive opening and closing movements. Tension is taken up at the exposed ends of the strap, until a satisfactory state of synergism has resulted. A tantalum clip, as used in retinal surgery, is applied and clamped, thus firmly fixing the silicone element. The clip is buried with deep sutures, the skin incisions are closed, and a light dressing is applied.

\section{Conclusion}

This technique offers a dynamic approach to facial nerve paralysis, producing an effective though nevertheless ersatz synkinesis of eyelid movement. Apart from the obvious cos-

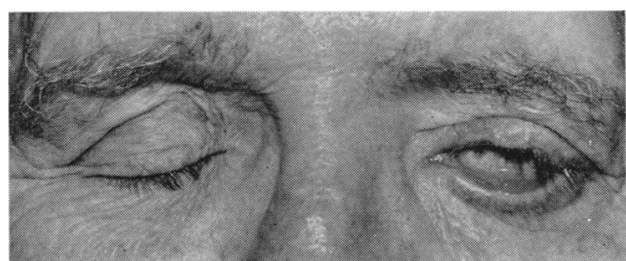

FI G. 3 Preoperative photograph of attempted closure of eyelids

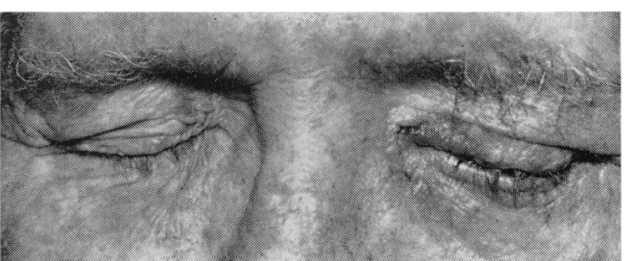

FIG. 4 Immediate postoperative photograph of attempted closure of eyelids 
metic advantage, it respects the role of the tear-film particularly in relation to the spread of mucus and enhances the congruity of eyelid to cornea in attempted closure. Figs 3 and 4 (see p. 751) show a typical case before and after operation.

We are indebted to Dr. W. Exton, Superintendent, Repatriation Hospital, Brisbane, and Dr. K. Hossack, Director of Medical Services, Repatriation Department, Brisbane, for their cooperation

\section{References}

ARION, H. G. (I972) Int. Surg., 57, $4^{8}$

english, f. P., and english, к. P. (1972) Med. J. Aust., r, 223

GUY, C. L., and RANSOHOFF, J. (I968) J. Neurosurg., 29, 43 I

levine, r. e., house, w. f., and hitselberger, w. e. (i972) Amer. J. Ophthal., 73, 2 ig

MOREL-FAtio, D., and LALARDRIE, J. P. (I967) "Palliative surgical treatment of facial paralysis:

The palpebral spring" in "Proc. II Int. Symp. Plastic and Reconstructive Surgery of the Eye and응.

Adnexa", ed. B. Smith and J. M. Converse, p. 38o. Mosby, St. Louis

smith, B., and cherubini, т. D. (I970) "Oculoplastic Surgery", p. i27. Mosby, St. Louis 